\title{
KECENDERUNGAN GAYA BELAJAR MAHASISWA PENDIDIKAN TEKNIK BANGUNAN
}

\author{
Suhardjono \\ Universitas Sebelas Maret, Jln. Ahmad Yani No.200 A Surakarta 57161 \\ Email: ha-djono@uns.ac.id
}

\begin{abstract}
: this research aims to know the various learning style that was adopted by student of Building techniques Education, and to know the tendency learning style student of Building techniques Education. The sample chose as random with using technical Election stratified with sample presentation which taken every strata is Sam. The research result about the tendency student learning style accodring to David kolb show the average scores High to lob is Diverger type (62,5\%); accomodator type (25,96\%); Converger type (6,73\%); and Assimilator type $(4,81 \%)$. On the other hand, student learning style according De Porter \& Hernacki show average scores from High to lob is Kinestetic (45,19\%); Visual (43,27\%); and auditorial $(11,54 \%)$
\end{abstract}

Keywords: learning style, tendency, David kol, de porter\&Hernacki

\begin{abstract}
Abstrak: Penelitian bertujuan untuk mengetahui berbagai gaya belajar yang dianut oleh mahasiswa Pendidikan Teknik Bangunan, serta mengetahui kecenderungan gaya belajar mahasiswa Pendidikan Teknik Bangunan. Sampel dipilih secara random dengan menggunakan teknik pemilihan berstrata dengan prosentase sampel yang diambil pada tiap strata adalah sama. Hasil penelitian tentang kecenderungan gaya belajar mahasiswa menurut David Kolb menunjukkan ha-sil rata-rata dari besar ke kecil adalah tipe Diverger (62,5\%); tipe Accomodator $(25,96 \%)$; tipe Converger (6,73\%); dan tipe Assimilator $(4,81 \%)$. Sementara gaya belajar mahasiswa menurut De Porter \& Hernacki menunjukkan hasil rata-rata dari besar ke kecil adalah Kinestetik $(45,19 \%)$; Visual (43,27\%); dan Auditorial (11,54\%).
\end{abstract}

Kata kunci: gaya belajar, kecenderungan, david Kolb, De porter\&Hernacki

\section{PENDAHULUAN}

Belajar adalah kegiatan yang secara sadar dilakukan. Dalam kegiatan belajar, seseorang menggunakan hampir semua panca indra dan pikirannya. Hasil yang diperoleh dari proses belajar disebut dengan hasil belajar. Salah satu faktor penting yang mempengaruhi pencapaian hasil belajar adalah pemahaman akan gaya belajar peserta didik. Masing-masing individu, termasuk peserta didik, memiliki gaya belajar berbeda. Senada dengan pendapat Mann \& Sabatina (1985) dalam Ardi H (2007) bahwa individu dengan IQ yang sama, kecakapan yang sama, dan kemampuan memproses informasi yang sama, dalam banyak hal akan berbeda dari cara mereka menerima sesuatu, cara berpikir, menyelesaikan berbagai persodan, dan mengingat sesuatu.

Naiman, et.a1. (1978) dalam Ardi H (2007) mengemukakan bahwa pengajaran bidang studi apapun, hanya bisa ditingkatkan kualitasnya, apabila pengajar memahami karakteristik peserta. didik dengan baik termasuk gaya belajar mereka. Kemudian, informasi tentang gaya belajar peserta didik tersebut menjadi bahan pertimbangan bagi pengajar dalam memilih metode, media pembelajaran, dan materi ajar yang sesuai dengan keberagaman gaya belajar peserta didik. Jika gaya belajar peserta didik dan gaya mengajar pengajar sejalan, maka banyak hal-hal positif yang bisa dicapai secara optimal seperti suasana belajar yang menyenangkan, meningkatnya motivasi belajar dan 
minat siswa terhadap pelajaran dan proses belajar, dan hasil belajar yang semakin meningkat.

Akan tetapi, dalam praktik pembelajaran di kebanyakan institusi pendidikan, informasi dari peserta didik, termasuk gaya belajar, belum dijadikan pertimbangan dalam pemilihm metode teknik, atau materi ajar pada hampir setiap tempat baik sekolah dasar, menengah, dan perguruan tinggi.

Kajian teoretis dan empiris menunjukkan bahwa peserta didik memiliki gaya belajar yang bervariasi, Di samping itu, juga disimpulkan bahwa hasil belajar yang optimal akan dicapai jika pendekatan mengajar, metode mengajar, teknik mengajar, materi ajar mengakomodasi gaya belajar peserta didik. Untuk itu, informasi tentang gaya belajar peserta didik perlu diketahui.

Atas pertimbangan tersebut, maka kecenderungan gaya belajar mahasiswa Pendidikan Teknik Bangunan perlu untuk diketahui, untuk selanjutnya dapat menjadi bahan pertimbangan bagi dosen dalam memilih metode maupun media pembelajaran yang sesuai dengan kecenderungan gaya belajar mahasiswa, agar diperoleh hasil belajar yang optimal. Oleh karena itu penelitian ini dilaksanakan dengan tujuan untuk mengetahui berbagai gaya belajar yang dianut oleh mahasiswa Pendidikan Teknik Bangunan, serta mengetahui kecenderungan gaya belajar mahasiswa Pendidikan Teknik Bangunan.

Gaya belajar merupakan suatu kombinasi dari bagaimana ia menyerap, dan kemudian mengatur serta mengolah informasi. Gaya belajar bukan hanya berupa aspek ketika menghadapi informasi, melihat, mendengar, menulis dan berkata tetapi juga aspek pemrosesan informasi sekunsial, analitik, global atau otak kiri-otak kanan, aspek lain adalah ketika merespon sesuatu atas lingkungan belajar (diserap secara abstrak dan konkret) (Maulida D, 2008).

Terdapat beberapa klasifikasi gaya belajar yang dikemukakan oleh beberapa ahli. Dalam penelitian ini, klasifikasi gaya belajar yang digunakan adalah klasifikasi menurut Dayid Kolb dan DePorter \& Hernacki.
Penelitian ini dilakukan di Program Pendidikan Teknik Bangunan FKIP UNS, dengan subjek penelitiannya adalah mahasiswa Pendidikan Teknik Bangunan FKIP UNS, dan objeknya adalah gaya belajar mahasiswa.

Populasi penelitian adalah mahasiswa Pendidikan Teknik Bangunan semester II sampai dengan semester VIII pada Tahun Akademik 2009/2010. Sampel dipilih secara random dengan menggunakan teknik pemilihan berstrata dengan persentase sampel yang diambil pada tiap strata adalah sama (proportional stratified random sampling technique). Jumlah sampel penelitian dihitung dengan menggunakan rumus dari Yamane (1967) dalam Sukandarrumidi (2002), yaitu:

$$
n=\frac{N}{N d^{2}+1}
$$

$\mathrm{n} \quad=$ jumlah sampul

$\mathrm{N} \quad=$ jumlah populasi

$\mathrm{D}=$ presisi, ditetapkan $5 \%$ (dengan tingkat konfidensi 95\%)

Jumlah sampel tersebut kemudian dibagi dengan jumlah strata atau tingkat semester mahasiswa, yaitu semester dua, semester empat, semester enam, dan semester delapan. Sehingga akhirnya diperoleh jurnlah sampel yang diperlukan dari tiap-tiap strata tersebut.

Data yang digunakan dalam penelitian ini bentpa informasi tentang gaya belajar yang dianut oleh mahasiswa Program Studi Pendidikan Teknik Bangunan. Tipe gaya belajar yang ditinjau adalah gaya belajar menurut David Kolb dan DePorter B. \& Hernacki M. Data tersebut dikumpulkan melalui sumber data penelitian, yaitu informan atau nara sumber, yaitu mahasiswa Program Studi Pendidikan Teknik Bangunan semester II sampai dengan semester VIII Tahun Akademik 2009/2010.

Data dikumpulkan melalui kuisioner yang diisi oleh perwakilan mahasiswa Program Studi Pendidikan Teknik Bangunan FKIP UNS sebagai sampel penelitian. kuisioner disusun berdasar pada karakteristikkarakteristik tiap-tiap tipe gaya belajar sesuai 
dengan tinjauan pustaka. Karakteristik untuk setiap gaya belajar dijadikan satu item pada kuisioner. Setiap item kuisioner disediakan empat alternatif jawaban: tidak setuju, sangat tidak setuju, setuju, sangat setuju. Masingmasing alternatif jawaban diberi bobot nilai yang berbeda: 1 untuk sangat tidak setuju; 2 untuk tidak setuju; 3 untuk setuju; dan 4 untuk jawaban sangat setuju.

Penelitian ini dikelompokkan pada jenis penelitian deskriptif karena tujuan penelitian adalah mengidentifikasi dan mendeskripsikan profil gaya belajar mahasiswa. Gaya belajar masing-masing sampel ditentukan oleh nilai rata-rata tertinggi yang dimiliki oleh peserta pada tiap kategori gaya helajar.

Sebelum diterapkan pada sampel penelitian, kuisioner diuji validitasnya pada bagian lain dari populasi. Item kuisioner yang terbukti tidak valid tidak akan dimasukkan dalam kuisioner yang digunakan pada sampel penelitian. Dalam penelitian ini, uji validitas dilakukan dengan menggunakan rumus korelasi product moment.

\section{HASIL DAN PEMBAHASAN}

Data yang diperoleh dari pengelola Program Studi Pendidikan Teknik Bangunan FKIP UNS menyebutkan bahwa jumlah mahasiswa Prodi PTB pada Tahun Akademik 2009/2010 adalah 141 orang, sehingga jumlah sampel yang diperlukan adalah:

$$
\begin{gathered}
n=\frac{N}{N d^{2}+1} \\
n=\frac{141}{141 x(0,05)^{2}+1} \\
n=104,25 \approx 104 \text { orang }
\end{gathered}
$$

\footnotetext{
Sampel sejumlah 104 tersebut
kemudian dibagi dengan jumlah strata atau

Sampel sejumlah 104 tersebut
kemudian dibagi dengan jumlah strata atau
}

tingkat semester mahasiswa di mana dalam penelitian ini diambil 4 tingkan semester, sehingga untuk masing-masing tingkat semester diperlukan sampel sejumlah 26 responden.

Uji validasi dilakukan dengan mengambil data isian angket dari mahasiswa di luar sampel penelitian. Untuk keperluan uji validasi ini, angket dikenakan pada 10 orang mahasiswa semester II, 10 orang mahasiswa semester IV, dan 10 orang mahasiswa semester VIII. Dengan jumlah angket total 30 responden, maka nilai $r_{\text {tabel }}$ sebagai nilai batas validasi diambil 0,361. Berdasarkan hasil uji validasi didapatkan beberapa item kuisioner yang dinyatakan tidak valid. Item-item yang tidak valid tersebut kemudian dikeluarkan dari angket yang akan digunakan untuk pengambilan data selanjutnya. Angket yang telah diuji validasi kemudian dikenakan pada sampel penelitian sesungguhnya.

Hasil penelitian tentang kecenderungan gaya belajar mahasiswa Pendidikan Teknik Bangunan FKIP UNS untuk karakteristik gaya belajar menurut David Kolb menunjukkan hasil rata-rata dari besar ke kecil adalah: tipe Diverger (62,5\%); tipe Accommodator $(25,96 \%)$; tipe Converger (6,73\%); dan tipe Assimilator (4,81\%). Dengan demikian, kecenderungan gaya belajar mahasiswa Pendidikan Teknik Bangunan pada karakteristik gaya belajar menurut David Kolb adalah tipe Diverger.

David Kolb (1981) dalam Meilania (2009) mengemukakan adanya empat kutub kecenderungan seseorang dalarn proses belajar, seperti diilustrasikan dalarn diagram pada Gambar 1 berikut. 

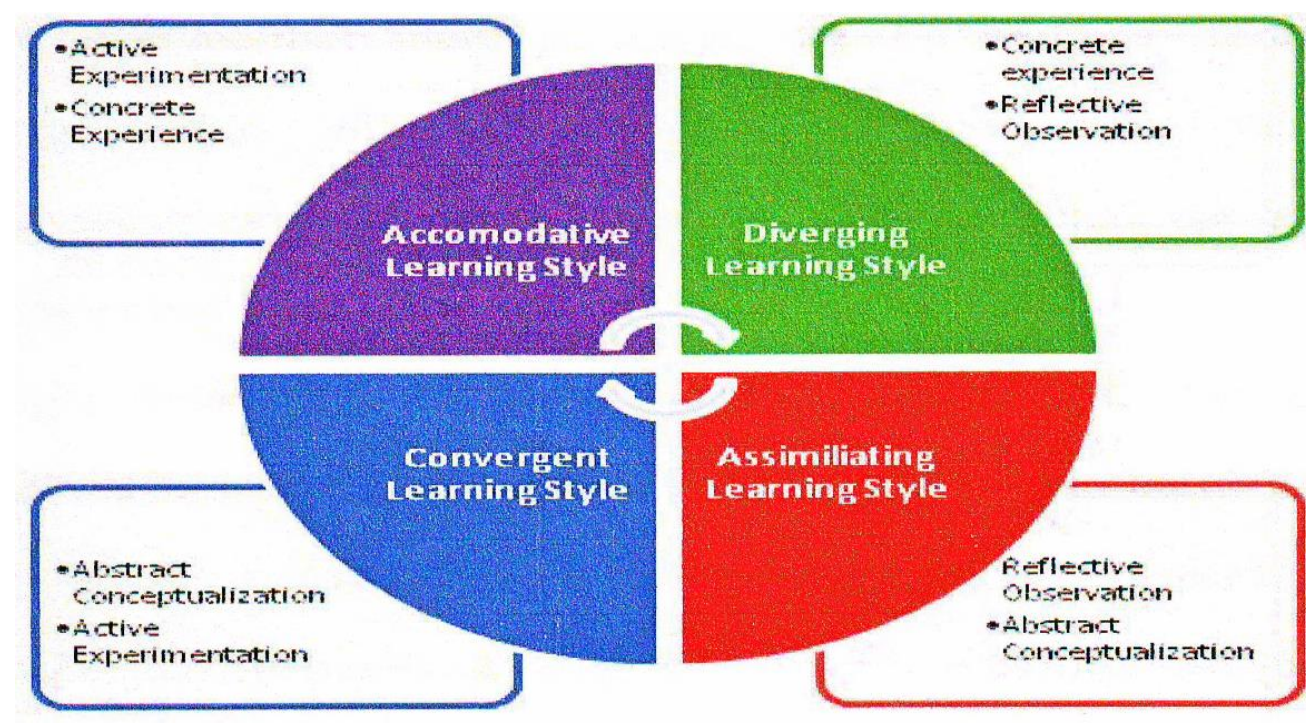

Sumber: Shaun Killian, 2009

\section{Gambar 1. Kutub Gaya Belajar Menurut David Kolb}

Gaya belajar tipe diverger merupakan perpaduan dari kutub perasaan/feeling (concrete experience) dan pengamatan/ watching (reflective observation). Pada kutub perasaan, seseorang belajar melalui perasaannya, dengan menekankan segi-segi pengalaman nyata atau konkret, serta lebih mementingkan hubungan dengan sesama dan peka terhadap perasaan orang lain. Dalam proses belajar, sesorang dalam kutub ini cenderung lebih terbuka dan mampu beradaptasi terhadap berbagai perubahan yang dihadapinya.

Sedangkan pada kutub pengamatan, seseorang belajar melalui pengamatan, di mana penekanannya pada kegiatan mengamati sebelum menilai, menyimak suatu perkara dari berbagai perspektif, dan selalu menyimak makna dari hal-hal yang diamati. Dalam proses belajar, seseorang dalam kutub ini akan menggunakan pikiran dan perasaannya untuk membentuk opini atau pendapat.

Karena tipe diverger adalah perpaduan dari kutub perasaan dan pengamatan, maka seseorang dengan tipe diverger memiliki keunggulan dalam melihat situasi konkret dari banyak sudut pandang yang berbeda. Daya imajinasi mereka sangat tinggi, sehingga memiliki kemampuan melihat suatu persoalan melalui berbagai sudut pandang yangber beda. Seorang seperti ini menyukai tugas belajar yang menuntutnya untuk menghasilkan ide-ide (brainstorming), biasanya juga rnenyukai isu budaya serta suka mengum-pulkan berbagai infomasi.

Setelah tipe diverger, rata-rata terbanyak berikutnya adalah gaya belajar tipe accommodator, yaitu sebanyak $25,96 \%$. Tipe ini memiliki bagian kutub yang sama dengan diverger, yaitu pada kutub perasaan/feeling (concrete experience), sedangkan kutub yang satunya adalah kutub tindakan/doing (active experimentation). Seseorang dengan accommodator memiliki kemarnpuan belajar yang baik dari hasil pengalaman nyata yang dilakukannya sendiri. Mereka suka membuat. rencana, dan melibatkan dirinya dalam berbagai pengalaman baru dan menantang, Mereka cenderung untuk bertindak berdasarkan intuisi atau dorongan hati daripada berdasarkan analisa logis. Kesarnaan gaya belajar tipe diverger dengan tipe accommodator adalah kecenderungannya menyukai belajar melalui pengalaman nyata (concrete experience).

Dua tipe gaya belajar menurut David Kolb yang dianut oleh minoritas mahasiswa Pendidikan Teknik Bangunan adalah tipe Converger (6,73\%); dan tipe Assimilator $(4,81 \%)$. Kesamaan dari kedua tipe gaya belajar ini adalah pada kecenderungannya 
belajar teoretis melalui konsep-konsep abstrak.

Hasil penelitian tentang kecenderungan gaya belajar mahasiswa Pendidikan Teknik Bangunan FKIP UNS untuk karakteristik gaya belajar menurut DePorter \& Hernacki menunjukkan hasil rata-rata dari besar ke kecil adalah: Kinestetik (45,19\%); Visual (43,27\%); dan Auditorial (11,54\%).

Seseorang dengan gaya belajar kinestetik belajar menggunakan indera peraba, dengan merasakan sesuatu menggunakan indera peraba (tangan). Orang dengan tipe kinestetik ini harus aktif mengerjakan sesuatu agar dapat mengerti, daripada sekadar duduk diam membaca, mencatat atau duduk diam mendengarkan guru/dosen mengajar. Mereka lebih suka dengan kegiatan yang menghendaki adanya gerakan seperti role play, drama, diskusi, atau debat. Mereka belajar melalui praktik langsung dan banyak menggunakan bahasa tubuh. Dengan tipe ini, mereka butuh praktik ketika mempelajari sesuatu. Tipe kinestetik ini sejalan dengan tipe diverger pada gaya belajar menurut David Kolb.

Seseorang dengan gaya belajar visual lebih suka memproses informasi melalui mengerti". Biasanya nmeka dengan tipe ini senang belajar dengan membaca (diam), dan memperhatikan orang mengerjakan sesuatu (senang diberi contoh). Kekuatannya berada pada apa yang bisa mereka lihat. Bagi mereka belaiar akan sulit dipahami tanpa dibantu oleh media yang dapat dilihat.

Seseorang dengan gaya belajar auditory mengandalkan indera pendengarannya saat belajar. Mereka lebih suka mendengar penjelasan. Kekuatan mereka berada pada telinga. Saat di ruang kuliah, mahasiswa dengan tipe auditory ini akan lebih mengerti pelajaran saat dosen memberikan penjelaan secara lisan ketika mengajar di depan kelas. Orang bertipe auditory umumnya akan mengeluarkan suara ketika menghafal sesuatu. Dia butuh sesuatu yang didengarkan oleh indera pendengarannya bahkan ketika dia sedang belajar sendirian. Data hasil penelitian ini menunjukkan hanya terdapat sedikit perbedaan antara rata-rata gaya belajar kinestetik dan gaya belajar visual. Dengan demikian dapat dikatakan kecenderungan gaya belajar mahasiswa Pendidikan Teknik Bangunan adalah melalui pengamatan langsung dan praktik nyata.

\section{PENUTUP}

Kesimpulan yang dapat diambil dari hasil penelitian ini adalah: (1) Mahasiswa Pendidikan Teknik Bangunan yang memiliki gaya belajar Diverger 62,5\%; Assimilator A 91\%; Converger 6,73\%; dan Accommodator 25,96 \%; (2) Mahasiswa Pendidikan Teknik Bangunan yang memiliki gaya belajar Visual 43,27\%; Auditorial 11,54\%; dan Kinestetik 45,19\%; (3) Kecenderungan gaya belajar mahasiswa Pendidikan Teknik Bangunan menurut David Kolb adalah tipe Diverger; (4) Kecenderungan gaya belajar mahasiswa Pendidikan Teknik Bangunan menurut DePorter \& Hernacki adalah tipe Kinestetik.

Melalui hasil penelitian ini dapat disimpulkan bahwa mahasiswa Pendidikan Teknik Bangunan memiliki kecenderungan belajar melalui pengalaman nyata. Kegiatan sebaiknya dilakukan sesuai dengan kecenderungan gaya belajar tersebut, untuk kegiatan di kelas melalui permainan, menyaksikan video, atau dengan diskusi kelompok. Kegiatan di luar kelas dilakukan melalui observasi lapangan, praktik lapangan ataupun praktik di laboratorium. Selain itu media pembelajaran juga disesuaikan, misalkan dengan menggunakan alat peraga pembelajaran berupa model-model atau miniatur elemen-elemen struktur, struktur lengkap bangunan, atau riil bahan bangunan, juga dengan menampilkan video-video pembelajaran sesuai dengan rnateri yang disampaikan.

\section{DAFTAR PUSTAKA}

Ardi, H. (2007). "Profil Gaya Belajar Ba-hasa Inggris Siswa SMA Negeri 7 Kota Padang". Jurnal Bahasa Sastra dan Seni Vol 1 Edisi Januari-April 2007, FBSS UNP.

Kaifa, M. D. (2008). "Pengaruh Gaya Belajar (Visual, Auditorial, dan Ki-nestetik) 
terhadap Prestasi Belajar Siswa Kelas I Penjualan SMK Muhammadiyah II Malang pada Mata Pelajaran Kewirausahaan Tahun Ajar-an 2007/2008".

Prayudi, Y. Y. (2007). "Gaya Belajar Individu", dalam http://www.e-psikologi.com/remaja/26092.htm diakses pada 14 April 2009.
Shaun, K. (2009). "David Kolb And Learning Styles”, dalam http://-effetive. leadershipdevelopment.-edu.au/david-kolb-learningstyles/experiential-learning diakses pada 10 Oktober 2010.

Sukandarrumidi. (2002). Metodologi Penelitian, Petunjuk Praktis untuk Peneliti Pemula. Yogyakarta: Gajah Mada University 